\title{
HYPERMETROPIC REFRACTIVE CHANGES IN A DIABETIC*
}

\author{
BY \\ I. SACKS \\ Bulawayo, Southern Rhodesia
}

THE text-books often mention remarkable changes in the refraction of the eye in diabetics-both in the direction of hypermetropia and in that of myopia. This is said to be due to alterations in the refractive index of the cortex of the lens, probably brought about by osmotic changes. I recently had occasion to see a newly-diagnosed case of diabetes which proved to be of great interest.

\section{Case Report}

The patient was a man aged 29. On examination his fasting blood sugar was $300 \mathrm{mg}$. per cent. His visual acuity was 6/18 in both eyes without correction. The lenses and fundi were normal.

Three weeks later his visual acuity was $6 / 6$ part in both eyes without correction, and was improved to:

$$
\text { Right Eye: } 6 / 5 \text { with } \frac{+0.50}{+0.50 \downarrow} \quad \text { Left Eye: } 6 / 5 \text { with } \frac{0}{+0.50}
$$

Ten days later he again complained of blurring of vision, and his visual acuity was found to be $6 / 18$ in both eyes without correction. This time it was improved to:

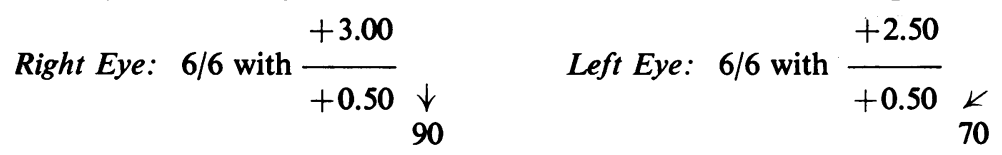

He could then read $\mathbf{J} 1$ easily with glasses.

One month later, when his diabetes was fairly well stabilized, there were slight colloid body-like changes around the macular area of both retinae, and some " rubeosis" of the conjunctivae. His visual acuity was $6 / 6$ part in both eyes without correction, and could be improved to:

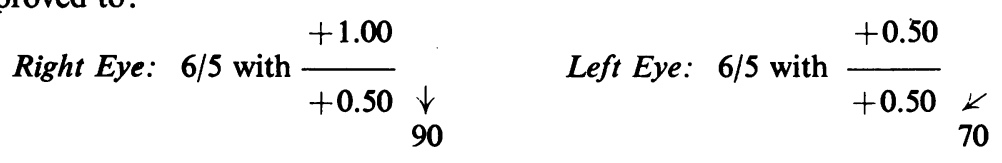

\section{Conclusions}

Definite hypermetropic refractive changes in a diabetic varied considerably with the different phases of "stabilization". It therefore seems advisable to wait until final stabilization is achieved before prescribing correcting lenses, despite the patient's occupational needs. 